\title{
Activity of insect juvenile hormone III: seed germination and seedling growth studies
}

\author{
Jacqueline C. Bede and Stephen S. Tobe \\ Department of Zoology, University of Toronto, 25 Harbord St., Toronto, Ontario, M5S 3G5, Canada
}

\begin{abstract}
Summary. Juvenile hormones are sesquiterpenoids that regulate developmental processses such as metamorphosis and reproduction in insects. Insect juvenile hormone III (JH III), methyl-10R,11-epoxy-3,7,11-trimethyl-2E,6E-dodecadienoate, has also been identified in two sedge species, Cyperus iria and C. aromaticus (Toong et al. 1988). Potential allelopathic activity of this compound and the structurally related sesquiterpenoid farnesol was investigated using seed germination and seedling growth assays with radish, lettuce and rice. Treatment of seeds with JH III delayed lettuce seed germination and potently inhibited rice shoot growth. Both farnesol and JH III inhibited the growth of $C$. iria seedlings. The antimicrobial activity of JH III was also tested on a taxonomic and ecologically diverse range of fungi. Using the classic cytotoxic disk assay, JH III did not effect growth of the fungal species tested. We believe that JH III may contribute to the aggressive nature of this invasive weed species.
\end{abstract}

Key words. Allelopathy - antifungal - Cyperus iria insect juvenile hormone III - sedge

\section{Introduction}

In the continual struggle against vertebrate and invertebrate herbivory as well as pathogen attack, sessile plants have evolved a diverse array of defensive strategies. One strategy against insect herbivory is the production of secondary metabolites that interfere with the physiology of the insect. In particular, targeting the endocrine system may make it difficult for the insect to develop counteradaptive strategies (Bowers 1991). These compounds may interfere with insect endocrine functions by mimicking hormones, such as the juvenile hormone $(\mathrm{JH})$ mimic, juvabione, originally isolated from Abies balsamea (L.) Miller, or the phytoecdysteroids. They may also interfere with the biosynthesis of these hormones, for example the precocenes, isolated from Ageratum houstonianum Miller, that destroy the endocrine site of JH production (Bowers et al. 1966, 1976; Adler \& Grebenok 1995). Recently, insect juve-

Correspondence to: S. S. Tobe, e-mail: stephen.tobe@utoronto.ca nile hormone III (JH III) and its biosynthetic precursor in insects, methyl farnesoate, were identified in the sedges, Cyperus iria L. and C. aromaticus (Ridley) Matt. \& Kük. (Fig. 1) (Toong et al. 1988). This was the first report of the presence of an insect $\mathrm{JH}$ in a plant.

In insects, the role of $\mathrm{JHs}$ in the regulation of metamorphosis and reproduction is well defined, although the mechanisms of action are not completely understood (Gilbert et al. 1996). During development, haemolymph $\mathrm{JH}$ titers are closely regulated. Therefore, topical application of $\mathrm{JH}$ or synthetic analogues to susceptible insects can result in the inappropriate retention of juvenile characteristics at the next moult (Sehnal 1983). Treatment of insect eggs with these compounds may cause immediate ovicidal or delayed developmental effects (Sehnal 1983).

The presence of JH III in C. iria suggests that this compound may protect the plant against insect herbivory. Developmental studies compared third stadium nymphs of the grasshopper, Melanoplus sanguinipes, reared on either wheat seedlings or C. iria (Toong et al. 1988). At the imaginal (adult) stage, grasshoppers reared on $C$. iria exhibited morphological abnormalities (e.g. twisted wings, colour changes) indicative of disrupted metamorphosis. Adult female grasshoppers were also infertile. Cyperus iria leaves were larvicidal following addition to water containing the mosquito, Aedes aegypti (Schwartz et al. 1998). Plant JHs may also affect insect egg development and, indirectly, subsequent herbivory. Eggs of the Dipteran leafminer, $\mathrm{Hy}$ drellia sp., did not hatch following oviposition on leaves of C. iria (Meneses-Carbonell \& Garciá de la Osa 1988).

In other studies, association with $C$. iria had no apparent effect on insect development in the planthoppers, Nisia strovenosa and $N$. nervosa, the rice water weevil, Lissorhoptrus brevirostris, the node-feeding black bug, Scotinophara latiuscula and the rice stink bug, Oebalus pugnax (Naresh \& Smith 1984; MenesesCarbonell 1985; Dela Cruz 1986; Barrion \& Litsinger 1987). It is unclear if the insect species in these last examples escaped the detrimental developmental effects of JH III through metabolism or sequestration of the ingested hormone or by avoidance of plant tissues containing high levels of this compound (Dowd et al. 1983; Lindroth 1991). 
Fig. 1 Structures of farnesol, methyl farnesoate and juvenile hormone III

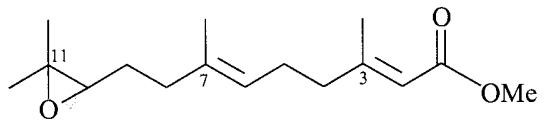

Methyl farnesoate: methyl-3,7,11-trimethyl-2E,6E,10-dodecatrienoate $\left(\mathrm{C}_{16} \mathrm{H}_{26} \mathrm{O}_{2}\right)$<smiles>COC(=O)/C=C(\C)CC/C=C(\C)CCC=C(C)C</smiles>

Farnesol: 3,7,11-trimethyl-2E,6E,10-dodecatrien-1-ol $\left(\mathrm{C}_{15} \mathrm{H}_{28} \mathrm{O}\right)$<smiles>CC(C)=CCC/C(C)=C/CC/C(C)=C/CO</smiles>

The ability of $C$. iria to interfere with insect development, presumably as a consequence of the presence of JH III, has clearly been demonstrated (Toong et al. 1988; Schwartz et al. 1998). However, conclusive evidence that this hormone protects the plant from insect herbivory has not been forthcoming. Sedges, such as $C$. iria, are nutritionally poor and contain high silica levels which are thought to deter insect herbivory (Vicari \& Bazely 1993). The basal meristematic tissue of these plants also allows them to tolerate herbivore grazing. Therefore, the objective of the present study was to explore other potential biological activities of JH III in the plant.

Cyperus iria is a tufted, annual sedge with a widespread distribution throughout Asia and Africa (Holm et al. 1977; Catling 1992). In many areas, this plant is an invasive weed of crops, particularly rice. In a search for allelopathic compounds, Komai et al. (1981) isolated methyl farnesoate and farnesol from the closely related sedge, C. serotinus Rottb. (Fig. 1). These compounds exhibited potent inhibitory activity on shoot growth of lettuce and rice seedlings and are also biosynthetic intermediates of JH III in insects (Schooley \& Baker 1985; Cusson et al. 1991). The structural similarities between these acyclic sesquiterpenoids suggest that JH III may play a similar role in C. iria (Fig. 1). The present investigation compared the allelopathic activity of JH III on seed germination and seedling growth of radish, lettuce and rice with the structurally related sesquiterpenoid farnesol, as its biological activity is well documented (Wardle \& Simpkins 1980; Wardle \& Short 1982; Wardle et al. 1986). The activity of these compounds on the growth of $C$. iria seedlings was also measured. In the second part of our study, the antimicrobial activity of JH III on a range of fungal species, representing plant pathogens, coprophilous and soil fungi, was determined.

\section{Material and methods}

\section{Plant material}

Sedges were grown from seeds obtained from Dr. Y. C. Toong (Penang, Malaysia) in the greenhouse. Plants were grown in organic potting mix and kept continuously moist. Temperatures ranged from approximately $22^{\circ} \mathrm{C}$ (winter) to ambient (summer). Voucher specimens of $C$. iria have been deposited at the Royal Ontario Herbarium, Canada (TRT).

Chemicals

All solvents used were HPLC grade from Burdick \& Jackson, unless otherwise noted.

Extraction of juvenile hormone III from roots of Cyperus iria

Juvenile hormone III was extracted from two to three month old plants. Root tissue was ground in acid-washed sand (Sigma) and liquid nitrogen and then extracted overnight in pentane at room temperature. The extract was evaporated to near dryness and subjected to column chromatography over an anhydrous sulphate (BDH)-hydroxyapatite column (HA, BioRad) to remove chlorophylls and other contaminants. A Pasteur pipette HA column was prewashed with ethyl ether $(5 \mathrm{ml})$ and iso-octane $(5 \mathrm{ml})$, before adding the sample, then washed with $5 \mathrm{ml}$ pentane and eluted with pentaneether $(70: 30)$. Following solvent evaporation under nitrogen (Canox), the sample was resuspended in hexane for final purification.

High performance liquid chromatography (HPLC)

Juvenile hormone III was purified from root extracts by HPLC (Perkin-Elmer 410 liquid chromatograph) by normal phase chromatography on a Spheri-5 silica column (Brownlee, $250 \times 4.6 \mathrm{~mm}$ ). The mobile phase was $10 \%$ half-water saturated ethyl ether in hexane at a flow rate of $1 \mathrm{ml} / \mathrm{min}$. Juvenile hormone III was monitored at $219 \mathrm{~nm}$ (Applied Biosystems 1000S Diode Array Detector) and identified on the basis of retention time relative to standards (Sigma, racemic, approx. $88 \%$ pure).

Stock solutions

Juvenile hormone III fractions collected from HPLC were pooled and the solvent evaporated. Juvenile hormone III stock solution was prepared in hexane and re-analyzed by HPLC to confirm the concentration. Stock solutions of farnesol ( $96 \%$ purity, mixture of isomers, Aldrich) were prepared in hexane.

Tritiated juvenile hormone III

Radiolabelled JH III was biosynthesized through the incubation of ${ }^{3} \mathrm{H}$-methionine with corpora allata (CA) from the cockroach, Diploptera punctata, followed by purification by HPLC (Tobe \& Clarke 1985; King \& Tobe 1988). The CA from day 5 mated female cockroaches were dissected and incubated in methionine-free TC 199 medium, containing 2\% Ficol (Pharmacia, Biotech), $1.3 \mathrm{mM}$ $\mathrm{CaCl}_{2} 2 \mathrm{H}_{2} \mathrm{O}$ (Analar, BDH), $40 \mu \mathrm{l}$ farnesoic acid (a gift of Dr. F. C. 
Baker, $70 \%$ pure) and L-[ ${ }^{3} \mathrm{H}$-methyl]-methionine (Amersham, specific radioactivity $3.11 \mathrm{TBq} / \mathrm{mmol}$ ) overnight at $27^{\circ} \mathrm{C}$. The aqueous medium was extracted twice with iso-octane. Pooled organic fractions were eluted through a silica column (Sep-pak, Millipore) and the resulting eluent evaporated under nitrogen and resuspended in hexane. Final purification of enantomerically pure $\left[{ }^{3} \mathrm{H}\right.$-methyl $]-10 R-\mathrm{JH}$ III was by HPLC. Again, the solvent was evaporated and the stock solution prepared in toluene. When used in an assay, ${ }^{3} \mathrm{H}-\mathrm{JH}$ III was added to a polyethylene glycol (PEG) (MW 15000-20 000, Sigma)treated scintillation vial $(20 \mathrm{ml}$, VWR Canlab). The toluene was evaporated under nitrogen and the solution prepared in hexane.

\section{Solubility of juvenile hormone III}

Tritiated JH III stock solution was prepared in hexane, an aliquot placed in a $2 \mathrm{ml}$ vial with cold JH III (Sigma, 0 to $8.8 \mathrm{mM}$ ) and the solvent evaporated. After the addition of $0.5 \mathrm{ml}$ sterile distilled water, vials were tightly capped and sonicated for 3 hours in a water-bath (Cole-Parmer, ultrasonic cleaner, 8845-4) to form finely dispersed micelles. The solution was allowed to settle for 3 days at room temperature. Four aliquots of the aqueous solution were removed using a disposable glass Accupette pipette (Canlab). Scintillation fluid (Cytoscint, ICN) was added and the radioactivity of the sample measured using a Beckmann LS 6500 Scintillation Counter $(N=3)$. The experiment was repeated twice.

The aqueous solubility of JH III was estimated to be $1.3 \mathrm{mM}$. This is in agreement with the predicted solubility of JH III which is $0.86 \mathrm{mM}$ (Advanced Chemistry Development) and the literature in which the solubility has been reported to be $>200 \mu \mathrm{M}$ in $5 \mathrm{mM}$ Tris-HCl, pH 8.3 (Kramer et al. 1976). It is also consistent with reports on the solubility range of oxygenated terpenoids (Weidenhamer et al. 1993). The biological assays in this paper were performed using JH III solutions between 0.01 to $1.0 \mathrm{mM}$, concentrations below its limit of solubility in aqueous solution. It should also be noted that JH III may be present in even higher concentrations in specialized compartments such as oil bodies in planta.

\section{Osmotic potential and $\mathrm{pH}$}

Osmolarity and $\mathrm{pH}$ may affect seed germination and seedling growth (Anderson \& Loucks 1966; Reynolds 1975a,b). The osmolarity and $\mathrm{pH}$ of JH III and farnesol solutions was measured using a Vapro vapour pressure osmometer $5520(N=3)$ and $\mathrm{pH}$ meter $(N=1)$ and compared to the hexane control. The osmotic potential of these solutions was $31.5 \pm 1.5$ and the $\mathrm{pH}$ was $7.05 \pm 0.04$. Therefore, any allelopathic activities observed were not the result of differences in osmolarity or $\mathrm{pH}$ between the test solutions and the control.

\section{Allelopathic assays}

The effects of farnesol and JH III on seed germination and seedling growth were tested on radish (Raphanus sativus L. var. Cherry Belle, McKenzie), lettuce (Lactuca sativa L. var. Grand Rapids, McKenzie) and rice (Oryza sativa L. cultivar AI-NAN-TSAO, seeds obtained from Dr. D. Saini (Montreal, Quebec)). Activities were also tested on C. iria seedling growth (seeds originally obtained from Dr. Y. C. Toong (Penang, Malaysia)). Under sterile conditions, $0.5 \mathrm{ml}$ of sterile distilled water and $50 \mu \mathrm{l}$ of test solution (hexane (control) or farnesol or JH III in hexane) were added to seeds on sterile filter paper (Ahlstrom) in 6 well plates (Nunc). Plates were incubated in a growth chamber under a $14: 10$ light-dark cycle $(22000$ lux $)$ at $26 \pm 2^{\circ} \mathrm{C}$. The following numbers of seeds (mean \pm SEM, median) were added to each well: radish $(52.5 \pm 0.7,51.5)$, lettuce $(54.5 \pm 0.9,53.0)$, C. iria $(102.1 \pm 7.0,85.0)$ and rice $(13.2 \pm 0.1,13.0)$. Percentage seed germination (defined as extension of the radicle $2 \mathrm{~mm}$ from the seed coat) was monitored over the next 3-5 days. For each plant species, six replicates were performed.

At days 3, 4 and 5 for radish, lettuce and rice, respectively, shoot and root tissues were excised, dried at $50^{\circ} \mathrm{C}$ overnight and dry weights recorded. At day 6 , the entire $C$. iria seedling was dried and weighed.
Affinity of juvenile hormone III for plastic

Juvenile hormone III adsorbs strongly to plastic (Giese et al. 1977). Its affinity for the plastic plates used in the allelopathic experiments was determined, using the procedure established for the seed germination and seedling growth assays. Tritiated JH III was added to the 6 well plate containing filter paper and an aqueous solution of cold $\mathrm{JH}$ III $(0.1$ to $1.0 \mathrm{mM})$. After three days, the medium was removed and extracted twice with iso-octane. The organic phases were pooled, evaporated and resuspended in $100 \mu \mathrm{l}$ of iso-octane. After addition of scintillation fluid, the radioactivity of the sample was measured $(N=3)$. Blanks were subtracted. The experiment was repeated twice. At all the concentrations tested $(0.01$ to $1.0 \mathrm{mM} \mathrm{JH} \mathrm{III)},>83.3 \%$ of the JH III was recovered. Therefore, in the assay, it is assumed that the concentration of JH III approximates the amount to which the seeds are exposed.

\section{Antifungal activity}

Five $\mu \mathrm{l}$ of test solution (JH III $(1.0 \mathrm{mM}$ or $10.0 \mathrm{mM})$ or hexane (control)) was added to a sterile disk (Ahlstrom, grade 601) placed 3 $\mathrm{cm}$ from the edge of a Petri plate (Fisher, $100 \times 15 \mathrm{~mm}$ ) containing 20 $\mathrm{ml}$ modified Leonian's agar (Malloch 1981). Fungal specimens were added by point inoculation approximately $3 \mathrm{~cm}$ from the disk. A diverse range of fungal species were tested: Phylum Oomycota: Pythium aphanidermatum (root rot agent); phylum Zygomycota: $\mathrm{Mu}$ cor piriformis (fruit rot), Absidia sp. (soil saprophyte), Micromucor $\mathrm{sp}$. (soil saprophyte); subphylum Basidiomycotina (Dicaryomycota): $\mathrm{Co}$ prinus patouillardii (coprophilous), Schizophyllum commune (wood decay fungus), Trametes versicolor (white rot of timber), Cryptococcus albidus (basidiomycetous yeast); Dicaryomycota, subphylum Ascomycotina: Alternaria alternata (foliar blight pathogen), Cladosporium cladosporioides (ubiquitous foliar blight), Epicoccum nigrum (foliar blight pathogen), Microsphaeropsis olivaceus (saprophyte), Trichophyton mentagrophytes (agent of human, "ringworm"), Arthoderma quadrifidum (soil inhabiting keratinophilic fungus), Ascobolus crenulatus (coprophilous), Iodophanus carneus (coprophilous), Botrytis cinerea (blight and rot disease of grape), B. allii (soft rot pathogen of onion), Sclerotinia sclerotiorum (ubiquitous foliar and vascular plant pathogen), Sclerotium cepivorum (white rot of onion), Beauveria sp. (insect pathogen), Trichoderma viride (mycoparasitic soil fungus), Fusarium oxysporum (crown rot and vascular wilt pathogen), Stachybotrys chartarum (cellulophilic indoor contaminant), Penicillium chrysogenum (food spoilage agent), P. funiculosum (mycoparasitic soil fungus), Sordaria fimicola (coprophilous) and Podospora araneosa (coprophilous). The zone of inhibition around the disk was measured $5-21$ days post-inoculation, depending on the rate of fungal growth $(N=2)$.

Statistics

Analyses were performed using the statistical package SPSS 7.5. One-way Analysis of Variance (ANOVA) was used to compare the effects of JH III on shoot, root and seedling growth. Statistical significance was determined using a Tukey HSD post-hoc test. Repeated measures ANOVA was used to analyze seed germination and fungal mycelial growth.

\section{Results}

\section{Effect of farnesol and juvenile hormone III on seed germination}

Farnesol significantly delayed germination of radish, lettuce and rice seeds (Fig. 2a, 2c and 2e). In the presence of $1 \mathrm{mM}$ farnesol, seed germination of radish, lettuce and rice was inhibited by $56.7 \%, 54.1 \%$ and $18.4 \%$ on days 2,3 and 2.5 , respectively. However, on days 3, 4 and 5, respectively, there was no significant 


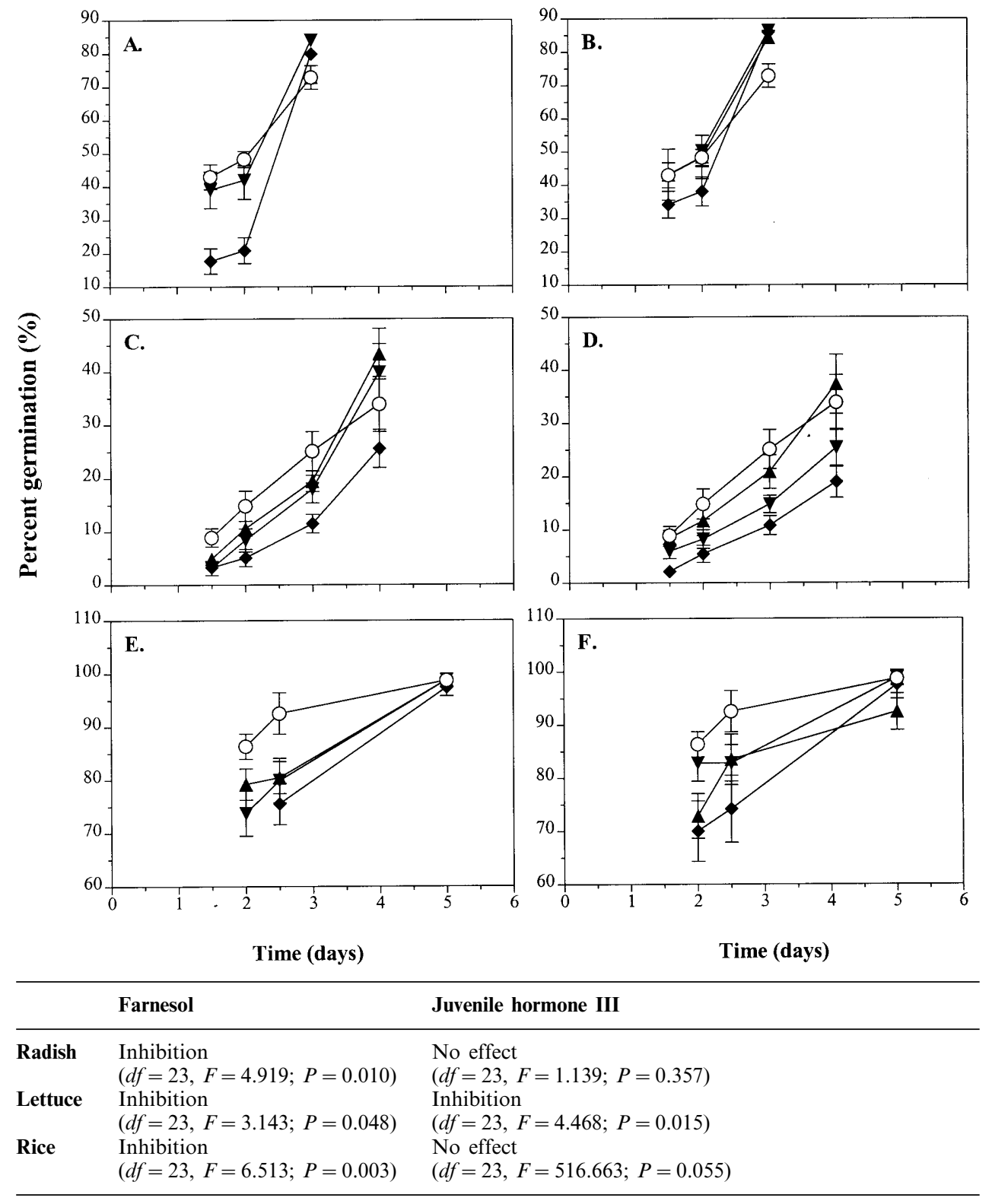

Fig. 2 Percent of radish (A and B), lettuce $(\mathrm{C}$ and $\mathrm{D})$ and rice $(\mathrm{E}$ and $\mathrm{F})$ seed germination after treatment by hexane control $(\bigcirc), 0.01 \mathrm{mM}(\mathbf{\Lambda})$, $0.1 \mathrm{mM}(\boldsymbol{\nabla})$ or $1.0 \mathrm{mM}(\boldsymbol{\nabla})$ of farnesol (A, C, E) or juvenile hormone III (B, D, F). Each point represents the mean of six experiments \pm standard error

inhibition of radish, lettuce or rice seed germination at any of the farnesol concentrations tested compared to the hexane control.

JH III did not affect radish or rice seed germination at the concentrations tested (Fig. 2b and 2f). A delay of lettuce seed germination was observed (Fig. 2d). In the presence of $1 \mathrm{mM} \mathrm{JH} \mathrm{III,} \mathrm{lettuce} \mathrm{seed} \mathrm{germination} \mathrm{was}$ reduced by $43.9 \%$ at day 4 .

\section{Effect of farnesol and juvenile hormone III on seedling root growth}

Application of farnesol to radish or lettuce seeds had no significant effect on root growth at the concentrations tested (Fig. 3a and 3c) whereas a concentrationdependent decrease in root growth was observed in the case of rice (Fig. 3e). Treatment of rice seeds with 1.0 $\mathrm{mM}$ farnesol resulted in a $28.0 \%$ inhibition of root growth.

Treatment of radish, lettuce and rice seeds with $\mathrm{JH}$ III did not significantly affect root growth, compared with hexane controls, at the concentrations tested (Fig. $3 b, 3 d$ and 3f).

\section{Effect of farnesol and juvenile hormone III on seedling shoot growth}

Neither farnesol nor JH III significantly affected shoot growth of radish or lettuce at the concentrations tested (Fig. $4 \mathrm{a}-\mathrm{d}$ ), whereas both reduced rice shoot biomass (Fig. 4e and 4f); $1.0 \mathrm{mM}$ farnesol and $\mathrm{JH}$ III inhibited growth by $36.8 \%$ and $24.0 \%$, respectively. 
Effect of farnesol and juvenile hormone III on Cyperus iria seedling growth

Cyperus iria seedlings were left intact and not separated into root and shoot tissue. Both farnesol and JH III inhibited the growth of these seedlings (Figs. 5a and b). At concentrations of $1.0 \mathrm{mM}$, growth of seedlings was only inhibited $5.1 \%$ and $6.7 \%$ by farnesol and JH III, respectively, relative to control values. Although there was an inhibition of the growth of $C$. iria seedlings, this may be offset by an accelerated sprouting of seeds that was observed only in the case of JH III-treated seeds (personal observation).

\section{Differences between farnesol and juvenile hormone III activity}

Farnesol and JH III are structurally related acyclic sesquiterpenoids (Fig. 1). In these assays, distinct bio- logical activities for farnesol and JH III on seed germination and seedling growth were observed. Both compounds inhibited the germination of lettuce seeds and the growth of rice seedlings shoots and $C$. iria seedlings. Farnesol and JH III had no effect on the root and shoot growth of radish or lettuce seedlings. However, farnesol has a broader range of activity and also inhibited radish and rice seed germination and the root growth of rice seedlings.

\section{Antifungal activity of juvenile hormone III}

No clear antimicrobial activity of JH III was observed on any of the fungi tested. However, variable inhibition of mycelial growth was observed in Ascobolus crenulatus and Sclerotinia sclerotiorum raising the possibility that there is a general inhibition of growth by this volatile compound rather than a discrete zone of inhibition.

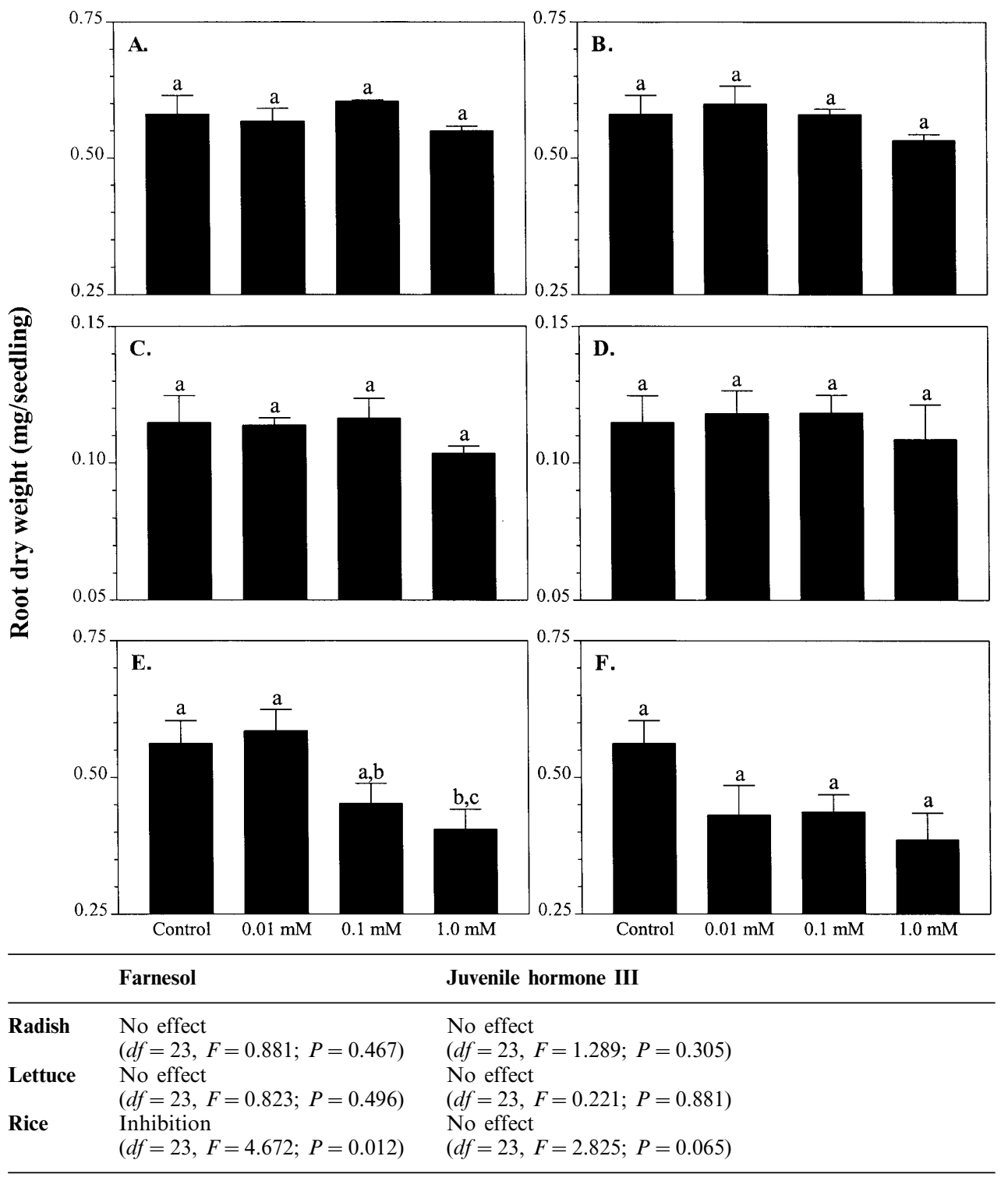

Fig. 3 Activity of the sesquiterpenoids farnesol $(\mathrm{A}, \mathrm{C}, \mathrm{E})$ and juvenile hormone III (JH III) (B, D, F) on radish $(\mathrm{A}$ and $\mathrm{B})$, lettuce $(\mathrm{C}$ and D) and rice (E and F) seedling root growth. The compound was applied to the seed and the root biomass (dry weight) was measured at 3,4 and 5 days after treatment for radish, lettuce and rice, respectively. Each bar represents the mean of six experiments \pm standard error. Bars with different letters are significantly different (one way ANOVA, $P<0.05$ ) 


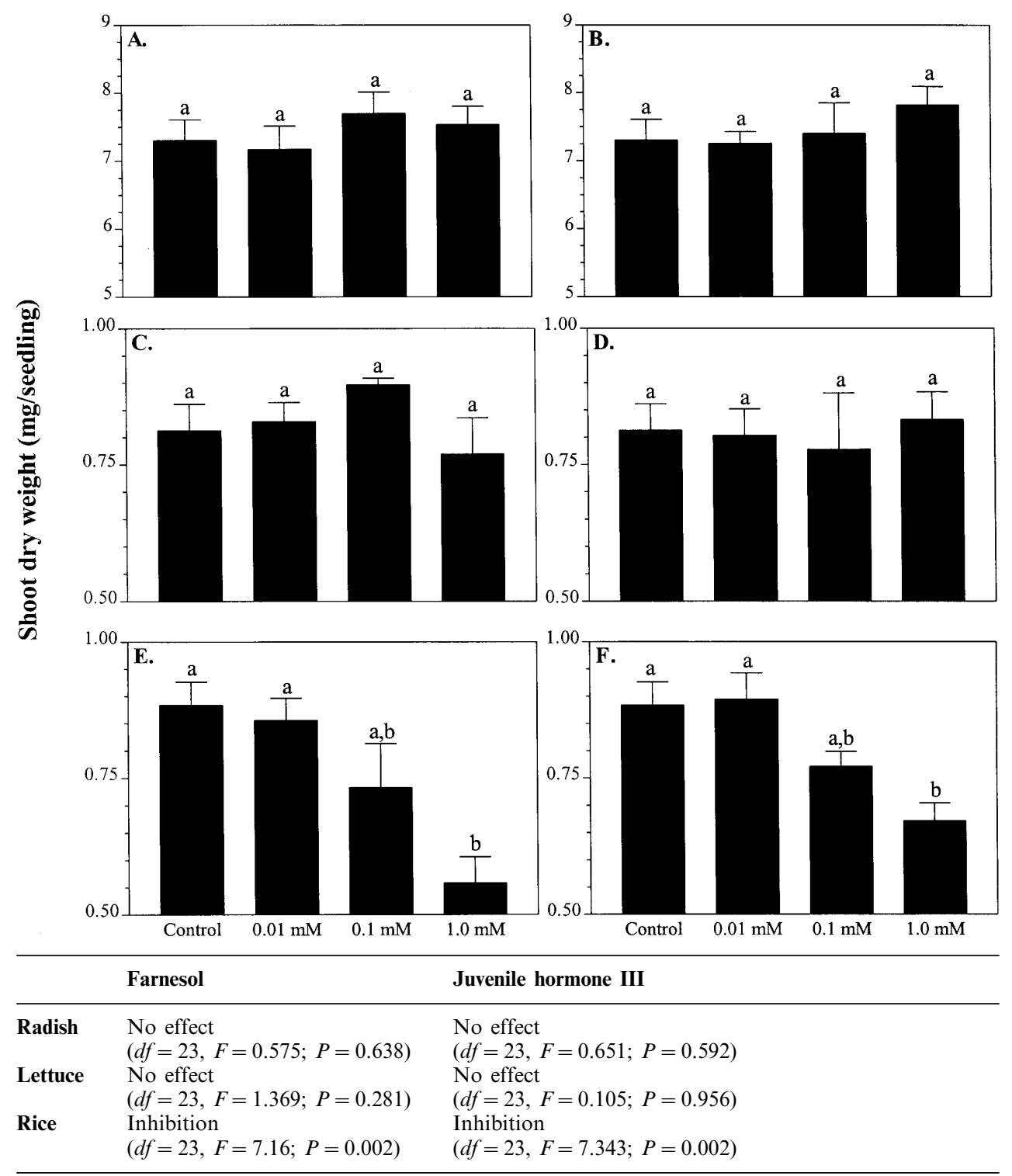

Fig. 4 Activity of farnesol (A, C, E) and juvenile hormone III (JH III) $(\mathrm{B}, \mathrm{D}, \mathrm{F})$ on radish (A and $\mathrm{B})$, lettuce $(C$ and $D)$ and rice $(\mathrm{E}$ and $\mathrm{F})$ seedling shoot growth. The compound was applied to the seed and the shoot biomass (dry weight) was measured 3, 4 and 5 days after treatment for radish, lettuce and rice, respectively. Each bar represents the mean of six experiments \pm standard error. Bars with different letters are significantly different (one way ANOVA, $P<0.05$ )

\section{Discussion}

The identification of JH III in C. iria and $C$. aromaticus is a unique example of the production of an insect juvenile hormone by a plant. The temporal and spatial distribution of JH III in $C$. iria demonstrates the dynamic fluctuations of this compound throughout development (Bede et al. 1999). In immature plants, JH III increased until flowering at which time cessation of plant growth and a transient decrease of JH III in all plant tissues was observed. In older plants, the levels of this compound increased until seven months. At this time, aerial tissues became senescent and JH III levels in these tissues again declined. However, JH III levels in the root tissue, which remained viable, did not change significantly between seven and eight months.
Most notably, during the entire growth phase, from the seedling to senescent plant, the highest levels of JH III were found in the root tissue. Roots of seven month old mature plants contained 102 nmoles JH III per gram fresh weight. This leads us to question the function of these high amounts of JH III that are produced by the plant and localized in the root tissues.

It is tempting to speculate that JH III may be involved in protection of the plant against insect herbivory. Since there is no evidence that JH III functions as a feeding deterrent, any antiherbivory activity would stem from its ability to interfere with insect development. However, there is only a short, stage-specific window during which treatment of an insect with $\mathrm{JH}$ III can potentially interfere with development (Nijhout and Wheeler, 1982). In fact, arrest of larval develop 


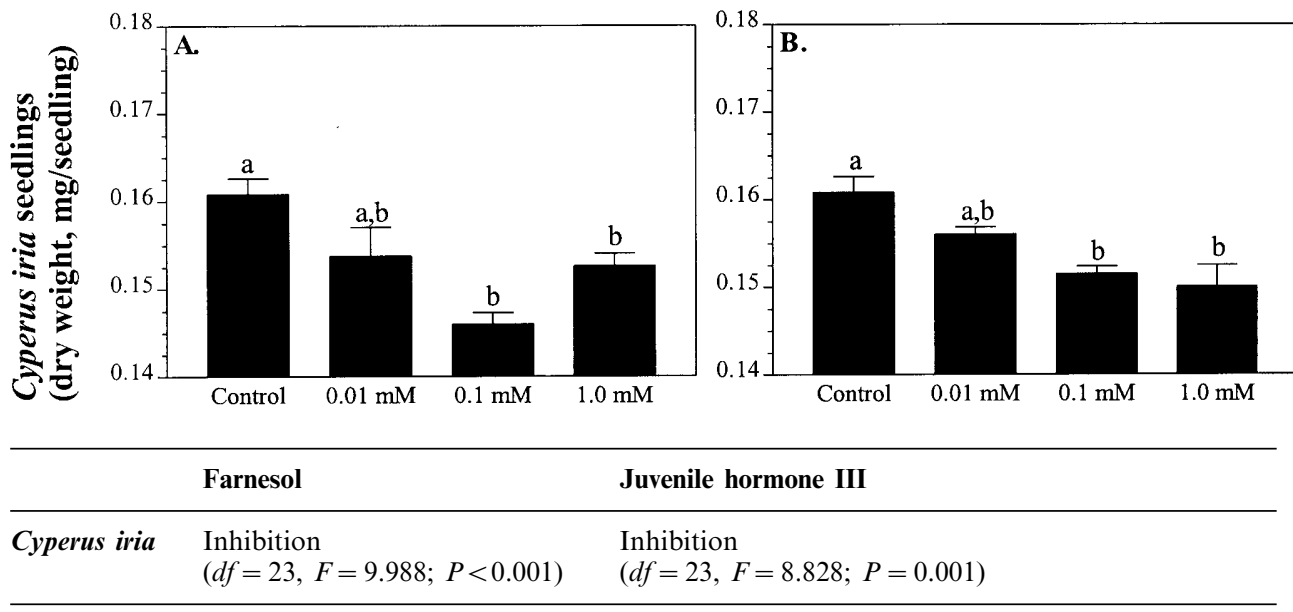

Fig. 5 Activity of farnesol (A) and juvenile hormone III (JH III) (B) on Cyperus iria seedling growth (dry weight). The compound was applied to the seed and the seedling was measured on day 6 after treatment. Each bar represents the mean of six experiments \pm standard error. Bars with different letters are significantly different (one way ANOVA, $P<0.05$ )

ment may prolong the feeding stage of the insect and result in increased consumption of the target plant. In adult insects, JH III can interfere with reproduction, if present at inappropriate times. However, there would be an appreciable lag time before a reduction in insect herbivory was noted, since the effects of JH III consumption by the female would only be manifested in the offspring. The present investigation evaluated the potential allelopathic and antimicrobial activity of $\mathrm{JH}$ III.

The observed allelopathic activities of farnesol were consistent with the literature. Inhibition of lettuce seed germination by farnesol was also observed by Wardle \& Short (1982) and Komai et al. (1981) who showed that $1 \mathrm{mM}$ farnesol did not affect lettuce seedling root elongation. However, contrary to our results, Komai et al. (1981) observed that $1 \mathrm{mM}$ farnesol did not affect rice root elongation and at higher concentrations, stimulation of root growth was observed. This discrepancy may have resulted from differences in rice cultivar, experimental conditions or the measurement parameters used. In the present investigation, seedling dry weight was used as an indicator of growth whereas Komai et al. (1981) directly measured root elongation. Wardle \& Short (1982) found that barley root elongation stimulated in the presence of farnesol $(83 \mu \mathrm{M})$ was the consequence of an increase in root meristem tissue (Wardle et al., 1986). However, a reduction in root hair formation was also observed. Therefore, farnesol may affect root elongation and dry weight differently. Komai et al. (1981) also reported that $1 \mathrm{mM}$ farnesol inhibited elongation of lettuce hypocotyls. Again, this differed from our results and these discrepancies can be attributed to differences in cultivars and/or experimental methodology.

Cyperus iria is an aggressive weed of many crops, particularly rice. In deepwater rice, this plant ranks among the worst weeds where it is prominent in marginal habitats before flooding (Pons 1985; Farjardo \& Moody 1990; Catling 1992; Sahid \& Hossain 1995).
The results from this study suggests that the invasive properties of C. iria may, in part, be attributable to $\mathrm{JH}$ III. This compound delayed germination of lettuce seeds. This activity may confer an ecological advantage to $C$. iria by affecting the germination of potential competitor plant species in the immediate vicinity. Juvenile hormone III also potently inhibited rice seedling growth; shoot biomass was $24 \%$ lower than controls in the presence of $1.0 \mathrm{mM} \mathrm{JH}$ III. This compound was also autotoxic to $C$. iria. Autotoxicity is a common phenomena observed in a number of plant species (Putnam \& Tang 1986; Rizvi \& Risvi 1992). However, the extent of inhibition of $C$. iria growth by JH III was much lower than its effect on rice shoot growth.

The question remains as to whether the concentration of JH III in the root rhizosphere is sufficient to exert a biological impact on competing plants. Allelochemicals are released from the roots into the environment through active exudation or leaching from dead and decaying tissue (Einhellig 1986). The undisturbed environment of the soil may allow released compounds to accumulate, forming a concentration gradient (Tang 1986). Retention of terpenoids has been observed in loam and clay soils (Dudai et al. 1999). The concentration in the root microenvironment may also increase through the formation of micelles, or through solubilization in biological surfactants (Einhellig 1986; Weidenhamer et al. 1993). Metabolites may also be directly transferred between plants through root grafts, fungal mycelial bridges or haustoria of parasitic plants (Rice 1984).

A further consideration in the evaluation of these data is that germination assays overestimate the amount of compound needed to obtain a response (Weidenhamer et al. 1987, 1994). Also, exposure to continual, "suboptimal" influxes of allelochemicals may be sufficient to elicit a biological response (Blum \& Rebbeck 1989; Williamson \& Weidenhamer 1990).

In this investigation, JH III $(1 \mathrm{mM})$ delayed lettuce seed germination and exerted a potent inhibitory effect 
on the shoot growth of rice seedlings. Mature $C$. iria plants contain approximately $1.2 \mu$ moles JH III per root. With the above examples of direct metabolite transfer, the possibility of increased concentration in the soil through retention and micelle formation and the demonstration that constant, low levels of allelochemicals can produce a biological response, it is possible that JH III contributes to the ecology of $C$. iria either through a delay in seed germination or an inhibition of the growth of competing plants. Further experimentation characterizing JH III levels in C. iria root leachates and the biotransformation of this compound in the soil must be conducted before conclusions about its biological function can be reached.

Terpenoids may also possess antimicrobial activity (Langenheim 1994). In the aromatic plant Satureja thymbra, the essential oils are believed to influence the ecology of the soil microbiota through the inhibition of fungal spore germination and growth and stimulation of bacterial growth (Vokou et al. 1984). JH III was not cytotoxic to any of the fungi tested. However, a minor decrease was observed in the mycelial growth of $A s$ cobolus crenulatus and Sclerotinia sclerotiorum. The latter fungus has been isolated from the related sedge species, C. rotundus (Singh \& Singh 1986) and is the causative agent of a number of economically important plant diseases (Agrios, 1988).

Structurally similar acyclic sesquiterpenoids have been isolated from several related Cyperus species, as well as unrelated plants. For example, the biosynthetic intermediate of JH III (in insects), methyl farnesoate, has been isolated from C. iria, C. microiria Steud., $C$. monophyllus Vahl., C. pilosus Vahl. and C. serotinus Rottb., as well as from grapes and the bark of Polyalthia viridis Craib (Iwamura et al. 1978a,b,c; Iwamura 1979; Iwamura et al. 1979; Toong et al. 1988; Kijjoa et al. 1990; Versini et al. 1994). The linear sesquiterpenoid methyl (E,E)-10,11-dihydroxy-3,7,11trimethyl-2,6-dodecadienoate has been isolated from a South American canopy tree, Hortia regia Sandwith., and an African rainforest tree, Cleistopholis patens (Benth.) Engl. and Diels and $\mathrm{Cl}$. staudtii (Engl. \& Pierre) (Waterman \& Muhammad 1985; Jacobs et al. 1987; Tane et al. 1988). This compound is identical to JH III except for the hydration of the epoxide to a vicinal diol. Because of the susceptibility of the epoxide to hydrolysis in the presence of trace amounts of acid or base, this compound may be an artifact produced from JH III by contaminants in the extraction solvent. Therefore, we believe that JH III may be present in other plant species, but the labile nature of this compound prevented its detection.

The isolation of JH III from two sedge species, its presence in $C$. iria throughout development and the identification of structurally similar compounds from a diverse range of plant species, suggests that this compound may have important biological roles in plants. The present investigation has demonstrated that treatment of seeds with JH III resulted in a delay of lettuce seed germination and the potent inhibition of rice seedling growth. Therefore, JH III may, at least in part, be responsible for inhibition of the germination and growth of surrounding plant species, providing $C$. iria with an ecological advantage. However, other potential biological functions of JH III, such as in plant defense against insect herbivory, bacterial or nematode invasion, or synergistic biological activities with other compounds cannot be discounted.

\section{Acknowledgements}

We are grateful to Dr. F. C. Baker (Zoecon, Corp., Palo Alto) for the generous gift of farnesoic acid, Dr. L. Buck (Dept. of Zoology, University of Toronto) for the use of his osmometer, Dr. L. Rowe (Dept. of Zoology, University of Toronto) for advice on statistics and J. R. Zhang (Dept. of Zoology, University of Toronto) for dissections of cockroach corpora allata. We thank the following people for the use of their fungal isolates: N. Alasti-Faridana, B. Couch, Dr. L. Kohn, Dr. D. Malloch and J. Scott (from the Dept. of Botany, University of Toronto) and Dr. R. Summerbell (Ontario Ministry of Health). We also thank Drs. W. G. Bendena and J. N. McNeil for critical reading of this manuscript and insightful comments. This research was supported by an operating grant from the Natural Sciences and Engineering Research Council of Canada (SST).

\section{References}

Adler JH, Grebenok RJ (1995) Biosynthesis and distribution of insect-moulting hormones in plants - a review. Lipids 30:257262

Agrios GN (1988) Plant Pathology, 3rd ed. San Diego: Academic Press

Anderson RC, Loucks OL (1966) Osmotic pressure influence in germination tests for antibiosis. Science 152:771-773

Barrion AT, Litsinger JA (1987) The bionomics, karyology and chemical control of the node-feeding black bug, Scotinophara latiuscula Breddin (Hemiptera: Pentatomidae) in the Philippines. J Pl Prot Tropics 4:37-54

Bede JC, Goodman WG, Tobe SS (1999) Developmental distribution of insect juvenile hormone III in the sedge, Cyperus iria L. Phytochemistry 52:1269-1274

Blum U, Rebbeck J (1989) Inhibition and recovery of cucumber roots given multiple treatments of ferulic acid in nutrient culture. $\mathbf{J}$ Chem Ecol 15:917-928

Bowers WS, Fales HM, Thomson MJ, Uebel EC (1966) Juvenile hormone: identification of an active compound from balsam fir. Science 154:1020-1021

Bowers WS, Ohta T, Cleere JS, Marsella PA (1976) Discovery of insect anti-juvenile hormones in plants. Science 193:542-547

Bowers WS (1991) Insect hormones and antihormones in plants. Pp 431-456 in Rosenthal GA, Berenbaum MR (eds) Herbivores, Their Interactions with Secondary Plant Metabolites, Vol. I. New York: Academic Press

Catling K (1992) Rice in Deep Water. London: International Rice Research Institute

Cusson M, Yagi KJ, Ding Q, Duve H, Thorpe A, McNeil JN, Tobe SS (1991) Biosynthesis and release of juvenile hormone and its precursors in insects and crustaceans: the search for a unifying arthropod endocrinology. Insect Biochem 21:1-6

Dela Cruz CG (1986) Host plant range of the planthopper Nisia atrovenosa. Int. Rice Res. Newsletter 11: 26-27 (Rev of Appl Ent (1986) 074-04038) 
Dowd PF, Smith CM, Sparks TC (1983) Detoxification of plant toxins by insects. Insect Biochem 13:453-468

Dudai N, Poljakoff-Mayber A, Mayer AM, Putievsky E, Lerner HR (1999) Essential oils as allelochemicals and their potential use as bioherbicides. J Chem Ecol 25:1079-1089

Einhellig FA (1986) Mechanisms and modes of action of allelochemicals. Pp 171-188 in Putnam AR, Tang C-S (eds) The Science of Allelopathy. New York: John Wiley \& Sons

Farjardo FF, Moody K (1990) Weed control and related cultural practices for wet-seeded rice (Oryza sativa L.) in Guimba, Nueva Ecija. Philipp J Weed Sci 17:51-64

Giese Ch, Spindler KD, Emmerich H (1977) The solubility of insect juvenile hormone in aqueous solutions and its adsorption by glassware and plastics. Z Naturforsch 32c:158-160

Gilbert LI, Rybczynski R and Tobe SS (1996) Endocrine cascade in insect metamorphosis. Pp 59-107 in Gilbert LI, Tata JR, Atkinson BG (eds) Metamorphosis. New York: Academic Press

Holm LG, Pluchnett DL, Pancho JV and Herberger JP (1977) Cyperus iria L. Pp 240-242 in The World's Worst Weeds. Honolulu: University Press of Hawaii

Iwamura J, Kameda M, Komai K and Hirao N (1978a) Studies on constituents in the Cyperaceae. II. The constituents of the essential oil from Cyperus microiria Steud. Nippon Kagaku Kaishi: 1552-1555 (Chemical Abstracts (1979) 90: 69086h)

Iwamura J, Kameda M, Komai K, Hirao N (1978b) The constituents of the essential oil from Cyperus iria L. Nippon Nogei Kagaku Kaishi 52:379-383

Iwamura J, Komaki K, Komai K and Hirao N (1978c) Studies on constituents in the Cyperaceae. V. The constituents of the essential oil from Cyperus monophyllus Vahl. Nippon Nogei Kagaku Kaishi 52:561-563 (Chemical Abstracts (1979) 90: 135072d)

Iwamura J (1979) The constituents of essential oils from Cyperus polystachyos Rottb., Cyperus globosus Allioni and Cyperus difformis L. Nippon Nogei Kagaku Kaishi 53:343-347 (Chemical Abstracts (1980) 92: 1162332f)

Iwamura J, Komaki K, Komai K and Hirao N (1979) Studies on consitutents in the Cyperaceae. IV. The constituents of the essential oil from Cyperus pilosus Vahl. Nippon Kagaku Kaishi: 255-258 (Chemical Abstracts (1979) 90: 164723x)

Jacobs H, Ramadayal F, McLean S, Perpick-Dumont M, Puzzuoli F, Reynolds WF (1987) Constituents of Hortia regia: 6,7dimethoxycoumarin, rutaecarpine, skimmianine, and (+)methyl

(E,E)-10,11-dihydroxy-3,7,11-trimethyl-2,6-dodecadienoate. J Natl Products 50:507-509

Kijjoa A, Pinto MMM, Pinho PMM, Tantisewie B, Herz W (1990) Clerodone derivatives from Polyalthia viridis. Phytochemistry 29:653-655

King LE, Tobe SS (1988) The identification of an enantioselective JH III binding protein from the haemolymph of the cockroach, Diploptera punctata. Insect Biochem 18:793-805

Komai K, Sugiwaka Y, Sato S (1981) Plant-growth retardant of extracts obtained from water nutgrass (Cyperus serotinus Rottb.). Memoirs of the Faculty of Agric of Kinki University 14:57-65

Kramer KJ, Dunn PE, Peterson RC and Law JH (1976) Interaction of juvenile hormone with binding proteins in insect haemolymph. Pp 327-341 in Gilbert LI (ed) The Juvenile Hormones. New York: Plenum Press

Langenheim J (1994) Higher plant terpenoids: a phytocentric overview of their ecological roles. J Chem Ecol 20:1223-1280

Lindroth RL (1991) Differential toxicity of plant allelochemicals to insects: Roles of enzymatic detoxication systems. Pp 1-33 in Bernays E (ed) Insect-Plant Interactions, Vol. III. Boca Raton: CRC Press

Malloch DW (1981) Moulds: Their Isolation, Cultivation and Identification. Toronto: University of Toronto Press

Meneses-Carbonell R (1985) Rice water weevil host plants in Cuba. International Rice Research Newsletter 10:21-22

Meneses-Carbonell R and Garciá de la Osa J (1988) [Principal weed hosts of Hydrellia sp. in the southern rice-growing zone of Sancti Spiritus, Cuba.] (Rev of Agr Ent (1991) 079-10772)

Naresh JS, Smith CM (1984) Feeding preference of the rice stink bug on annual grasses and sedges. Entomol Exp Appl 35:89-92
Nijhout HF, Wheeler DE (1982) Juvenile hormone and the physiological basis of insect polymorphisms. Q Rev Biol 57:109-133

Pons TL (1985) Growth rates and competitiveness to rice of some annual weeds. Biotrop Bulletin 23:13-21

Putnam AR and Tang C-S (eds) (1986) The Science of Allelopathy. New York: John Wiley \& Sons

Reynolds T (1975a) Characterization of osmotic restraints on lettuce fruit germination. Ann Bot 39:791-796

Reynolds T (1975b) pH restraints on lettuce fruit germination. Ann Bot 39:797-805

Rice EL (1984) Allelopathy, 2nd edition. New York: Academic Press, 309-319

Rizvi SJH and Risvi V (eds) (1992) Allelopathy: Basic and Applied Principles. New York: Chapman \& Hall

Sahid IB, Hossain MS (1995) The effects of flooding and sowing depth on the survival and growth of five rice-weed species. Plant Protection Quarterly 10:139-142

Schooley DA and Baker FC (1985) Juvenile hormone biosynthesis. Pp 363-389 in Kerdut GA, Gilbert LI (eds) Comprehensive Insect Physiology, Biochemistry and Pharmacology, Vol. 7. New York: Pergamon Press

Schwartz AM, Paskewitz SM, Orth AP, Tesch MJ, Toong YC, Goodman WG (1998) The lethal effects of Cyperus iria on Aedes aegypti. J Amer Mosquito Control Assoc 14:78-82

Sehnal F (1983) Juvenile hormone analogues. Pp 657-672 in Downer RGH, Laufer H (eds) Endocrinology of Insects. New York: Alan R. Liss

Singh UP, Singh RB (1986) Some new hosts of Sclerotinia sclerotiorum from India. Indian Phytopath 39:626

Tane P, Ayafor JF, Sodengam BL (1988) A substituted cinnamoyl ester from Cleistopholis staudtii. Phytochemistry 27:3986-3988

Tang C-S (1986) continuous trapping techniques for the study of allelochemicals from higher plants. Pp 113-131 in Putnam AR, Tang C-S (eds) The Science of Allelopathy. New York: John Wiley \& Sons

Tobe SS, Clarke N (1985) The effect of L-methionine concentration of juvenile hormone biosynthesis by the corpora allata of the cockroach, Diploptera punctata. Insect Biochem 15:175-179

Toong YC, Schooley DA, Baker FC (1988) Isolation of insect juvenile hormone III from a plant. Nature 333:170-171

Versini G, Rapp A, Dalla-serra A, Pichler U, Ramponi M (1994) Methyl trans geranate and farnesoate as markers for Gewürztraminer grape skins and related distillates. Vitis 33:139-142

Vicari M, Bazely DR (1993) Do grasses fight back? The case for antiherbivore defences. Trends in Ecology and Evolution 8:137141

Vokou D, Margaris NS, Lynch JM (1984) Effects of volatile oils from aromatic shrubs on soil microorganisms. Soil Biol Biochem 16:509-513

Wardle K, Simpkins I (1980) Response of cultured embryos of Phaseolus vulgaris and Hordeum vulgare to farnesol. Ann Bot 46:505-510

Wardle K, Short KC (1982) Effects of isoprenoid alcohols and fatty acids on root elongation, germination and their association with stomatal activity. Biochem Physiol Pflanzen 177:210-215

Wardle K, Dalsou V, Roberts AV, Short KC (1986) Characterization of the effect of farnesol on roots of barley. J Plant Physiol 125:401-407

Waterman PG, Muhammad I (1985) Sesquiterpenes and alkaloids from Cleistopholis patens. Phytochemistry 24:523-527

Weidenhamer JD, Morton TC, Romeo JT (1987) Solution volume and seed number: often overlooked factors in allelopathic bioassays. J Chem Ecol 13:1481-1491

Weidenhamer JD, Macias FA, Fischer NH, Williamson GB (1993) Just how insoluble are monoterpenes? J Chem Ecol 19:17991807

Weidenhamer JD, Menelaou M, Macias FA, Fischer NH, Richardson DR, Williamson GB (1994) Allelopathic potential of menthofuran monoterpenes from Calamintha Ashei. J Chem Ecol 20:3345-3359

Williamson GB, Weidenhamer JD (1990) Bacterial degradation of juglone: evidence against allelopathy? J Chem Ecol 16:17391741 